\title{
Book Review Essay
}

\section{Identity, History and Political Violence}

By Nick Brooke

A Review of:

Confounding Powers: Anarchy and International Society from the Assassins to Al Qaeda. By William J. Brenner. 2016. Cambridge: Cambridge University Press. 276pp.

The Taliban's Virtual Emirate: The Culture and Psychology of an Online Militant Community. By Neil Krishan Aggarwal. 2016. New York: Columbia University Press. $211 \mathrm{pp}$.

Friction: How Conflict Radicalises Them and Us [Revised and Expanded Edition]. By Clark McCauley and Sophia Moskalenko. 2017. Oxford: Oxford University Press. 303pp.

Misunderstanding Terrorism. By Marc Sageman. 2017. Philadelphia: University of Pennsylvania Press. 213pp. 
The events of September $11^{\text {th }} 2001$ impacted the world immediately, drastically and in a variety of ways. One particular effect was a generation of students and scholars drawn to understand how human beings could behave so destructively towards others. Since then an ever-expanding body of research has applied a variety of approaches to address these questions. The four monographs reviewed in this essay all focus on terrorism, its impact, performers and message, often drawing important lessons from the study of psychology, but differ in their topic, period and methodological approach. Initially, I will treat each individually, before highlighting common themes emerging from their distinct, but complementary, accounts.

In Confounding Powers, William Brenner adopts a theoretical approach to understand Al Qaeda's emergence, and explain how shifting conditions in the international system facilitated this process. Brenner's focus is on the role of the international system, systemic change over time, and the actors departing from established systemic norms that confound the international powers of their era through their "dissimilating" behavior (p. 3). Brenner's thesis is that these rising challenges to the system are given fertile ground in which to grow by the decline of dominant powers, and suggests that (historically), these challenges to both physical and ontological security have been sustained over decades, an ill-boding prediction. The role of key leaders is also highlighted as important in sustaining this challenge (p. $251-$ 252).

To study this phenomenon, Confounding Powers draws from the past by examining the historical developments of his three other cases: (1) the Nizari Ismailis (often referred to as the Assassins), (2) Genghis Khan and the Mongols, and (3) the pirates of the Barbary Coast. Brenner focuses on the Nizari Ismailis and their successes first in Persia and then in modernday Syria at taking and holding mountain fortresses in the face of the Seljuk Empire, and the impact this had upon the established regional powers. This rich and detailed discussion is fascinating, and beneficial for students and scholars of terrorism as the Assassins are often held up as the historical antecedents of Al Qaeda and other terrorist groups. Particularly notable is a discussion of the Ismaili missionary network ( $\left.d a^{\prime} w a\right)$, and this network's importance in birthing and sustaining the movement.

A key element, and legacy, of the Nizari Ismailis was their use of targeted assassination, and Brenner highlights the impact the group had in shaping (or hardening) norms of 'acceptable' 
behavior, especially around assassination. A historiographical examination of the development of assassin myths and stories illuminates subsequent depictions of the group as un-civilized savages, and the ways in which their legacy has been invoked to underscore the threat posed by a variety of antagonistic actors (p.96-106). Scholars of political violence can draw parallels between this phenomenon and the pejorative and varied application of the term 'terrorism' in the last century.

In studying Al Qaeda, Brenner takes us back to the group's roots in the Soviet invasion of Afghanistan in the 1980s. His nuanced approach challenges the belief that the United States was directly responsible for funding early iterations of the group, but does accept that the financial support available to insurgent groups, from the US and other sources made it possible for Osama bin Laden and others to build their network following the end of the conflict and the collapse of the Soviet Union. And it is this collapse that Brenner holds as central to creating conditions under which Al Qaeda could challenge the dominant actor in the new unipolar system. Brenner challenges the assertion that Al Qaeda's emergence and post-9/11 events are evidence of a 'clash of civilisations' as posited by Samuel Huntington (1993), instead suggesting that Al Qaeda is engaged in a clash with civilization (p. 201).

One aspect with which the author could have engaged is the extent to which Al Qaeda's emergence and the success of the September $11^{\text {th }}$ plot owes much to fortune, especially the missed opportunities to deal with Al Qaeda prior to the attack and the oft-highlighted 'intelligence failures' that allowed the group to plan and train. Whilst Brenner astutely identifies a number of key conditional developments necessary for Al Qaeda to be in the position to carry out this attack, it is clear that $9 / 11$ is centrally important to the systemic disruption that occurred. How effectively Al Qaeda would have been able to confound key international actors had 9/11 failed merits further discussion, and this could develop into an important conversation comparing the importance of long-term structural developments with significant individual events to the structural shifts Brenner identifies.

In his concluding remarks, Brenner wisely cautions against overreach in the war of ideas against Al Qaeda, ISIS and their supporters. Drawing on the lessons outlined in the text, Brenner suggests that "correcting misrepresentations", enabling the organic formation of norms and identities that reject the violence of these groups (p. 260), and focusing on their actions rather than "an innate evil nature" (p. 264) will reap rewards. Equally important is 
treating groups such as ISIS differently from other violent groups operating in the Middle East (such as Hamas) that may have a broader level of support (p. 261). Confounding Powers is a fine addition to the scholarship that seamlessly contributes valuable insight to a series of important discussions.

As demonstrated in Brenner's work, Al Qaeda, its allies and its successors have been center stage since 9/11. Routinely (and foolishly) ignored after international attentions shifted to Iraq are the Taliban, a group that achieved elements of what Al Qaeda sought during their rule in Afghanistan. With a vast quantity of material and interest directed at every Al Qaeda press release, it is somewhat surprising that no equivalent study has been undertaken of the Taliban's messaging. In The Taliban's Virtual Emirate, Neil Aggarwal addresses this, providing a rich and thorough examination of the Taliban's media output, the voice(s) with which they engage, the themes within their messaging, and the psychological and cultural considerations central to their media strategy. Aggarwal compares and contrasts the approaches taken in English, Arabic (global languages), Urdu and Dari (regional or national languages), and highlights an "ideological flexibility" (p. 6) on aspects like identity, the role of leadership, and governance.

In many ways, this is an in-depth study of a multilingual marketing campaign, although such crude reductionism would do a tremendous disservice to a thorough and fascinating engagement with an important (and understudied) political actor, an analysis that provides insight into the ways in which terrorist actors engage multiple audiences. Every detail that can be gleaned about terrorist narrative and messaging is central to understanding why it is effective and how this effectiveness can be curtailed. Beyond simply focusing on the message, Aggarwal draws on the work of Benedict Anderson (1991) to understand how the Taliban present themselves as an imagined community. Virtual Emirate has many meanings here! Central to this community is a "common identity [forged] by distinguishing between good and evil steeped in a distinct interpretation of Islam”, (p. 24), attempting to cut across linguistic and ethnic boundaries.

Aggarwal's engagement with the source material is skilfully woven throughout the text, allowing the reader to experience directly the subtle nuances in the Taliban's proclamations. The second chapter focuses specifically on the role of leadership, and the leadership of Mullah Omar, tracing his journey from "village mullah" to "Commander of the Faithful" for 
a worldwide community (p. 63). Mullah Omar is revealed to be strict, demanding "full obedience" (p. 52), a single-minded actor (p. 54) and enjoying a luxurious private lifestyle despite a more modest public appearance (p. 55).

One of the key contributions of this fine work is the distinction Aggarwal weaves between the Taliban's differing geographic identities:

"In-group identity forged through Islam underlies constructions in all languages, but a sense of regionality pervades these texts through tropes of nationalism in vernacular Dari, South Asian regionalism in parochial Urdu, the Muslim world in cosmopolitan Arabic and 'the West' in global English" (p. 87)

Similarly, in terms of out-groups, Aggarwal notes "even though Taliban authors vilify Christians and Jews in all four languages, varying cultural commitments lead authors to demonise additional out-groups, related to each language's geographical reach" (p. 85).

Throughout the text, The Taliban's Virtual Emirate highlights the impact of 9/11 on the Taliban and the ways in which it operated, communicated and recruited. The adoption of multilingual (and thus multi-audience) media output contrasted "pointedly from pro-Pashto policies during its short rule" prior to the invasion of Afghanistan in late 2001 (p. 13). Aggarwal terms the post-9/11 iteration of the group as the 'neo-Taliban' (p. 14), pulling together those "aligned with the transnational Islamist movement of Al Qaeda and those committed to Pashtun nationalism", whose ire is directed at the Afghan government and those that support it (p. 14). There are lessons to be learned about how militant groups learn and adapt to changing circumstances.

Somewhat notable is that violence is almost absent from the discussion. This is indicative of the fact that to understand terrorist actors, we must study more than just the violent behaviors of a group to learn about its true character, as this text and the work of scholars such as Thomas Hegghammer (2017) demonstrates. However, this does not mean that their violent actions should be obscured - our interest in the group is precisely because it is violent, and the Taliban's Virtual Emirate does seem to slightly discount this. This does not detract from a remarkably insightful and rich account that further develops our understanding of terrorist 
messaging and identity formation, and sheds light on an oft-ignored militant group and the communities it aspires to represent.

Identity (on many levels) is central also to the work of Clark McCauley and Sophia Moskalenko, scholars of 'radicalization', whose important 2008 paper on the topic remains the most accessed article submitted to the journal Terrorism and Political Violence. In Friction, the authors revisit the earlier edition of their work (2011) to supplement further study with relevant discussions. The text studies 'radicalization', which took on buzzword status among policymakers and scholars of political violence following an increase in 'homegrown' terrorism in the early 2000s. Like many other terms in the study of terrorism and political violence, 'radicalization' was applied haphazardly and often applied to a range of behaviors. This risked a failure to understand - and effectively respond to - why individuals became involved in violent activity.

Importantly, Friction begins by explaining to the readers what terrorists are not: they are not mentally ill (p. 2-3), they are not simply evil (p. 3), they are not a product of ideology or religion (p. 5), and they are just like us. McCauley and Moskalenko are clear that this is not only a transformation limited to those involved in terrorist violence, and suggest that after 9/11, Americans "were radicalized: our feelings, beliefs, and behaviors all moved toward increased support for violence against perceived enemies, including sometimes Arab and Muslim Americans" (p. 4). Friction fulfils a vital role, providing clarity and explaining the ways in which radicalization occurs and the different forms this process can take.

To achieve this, McCauley and Moskalenko study the $19^{\text {th }}$ century Russian terrorist group Narodnaya Volya (People's Will), its members and trace their introduction to (and involvement in) political violence, before explaining the relevant psychological processes and introducing analogous contemporary cases. The micro-level focus on a varied cast of characters allows the authors to show how different members of the same group often arrived at the same destination by taking different routes. Particularly fascinating in the historical narrative accounts of Narodnaya Volya members are discussions on the policy of 'going into the people' to spread their ideas, and of the role of student communes - demonstrating an understanding of the need to rely and draw on a wide support network, but also of the influencing power of tight-knit, like-minded communities, a theme central to the work of Marc Sageman, discussed below. 
The structure of the work is clear and effective, grouping factors in individual, group and societal level, before examining distinct aspects of each individually - focusing on processes such as personal grievance (Ch. 2), the importance of status (Ch. 6), the competition between groups (Ch. 9) and the influence of martyrdom (Ch. 13). In some ways this is problematic as it seems to suggest that each individual was influenced solely by one factor - however, the authors later acknowledge that mechanisms may combine (p. 278). What Friction does clearly, aided by this approach, is to demonstrate the wide variety of ways in which people come to view violent political action as a logical and rational direction to pursue. Thus, Friction is an essential and valuable resource for all scholars of terrorism, enabling its readership to more accurately address arguably the subject's most important question: why do people become terrorists?

The final text studied is also one that wrestles with this question, but is less convinced that it has been satisfactorily answered. In Misunderstanding Terrorism, Marc Sageman is clear the state, the media, the public, even some in academia do not understand terrorism, and their misunderstanding of the threat is contributing to its continued exacerbation. In many ways, Misunderstanding Terrorism feels like a personal account - the opening chapter traces the development of Sageman's career and understanding on these topics. Sageman is critical of particular approaches (suggesting that sophisticated analytical methods could not reveal much due to the poor quality of data) and particular scholars and sets out his intention to correct a series of key misunderstandings.

To demonstrate the extent to which politicians have overblown the threat from terrorism, the media and others, the author focuses the first two chapters on providing an accurate assessment of the threat posed to the West by terrorism. To achieve this assessment, Sageman compiles a dataset of 'neojihadi'(the term the author applies to refer to Islamic extremist groups) plots or attacks against the West since September 2001. Sageman found 66 in total and highlights changing patterns (a shift from top-down to bottom-up; an increasingly homegrown, simplistic threat), before using this data to draw on probability theory and assess the frequency with which specific communities should produce individuals who become involved in terrorism. This data is then contrasted with the number of people suspected of involvement in terrorism (by drawing on data from no-fly lists) to show that states are vastly 
over-stating the threat. In doing so, Sageman addresses a key misunderstanding of terrorism the scale of the threat.

It is also clear from Sageman's account who is responsible for misrepresenting this threat: the media and politicians. Throughout this work, Sageman scolds both. Politicians, we are told, "amplify the threat...for their own political gains and mislead the public into misunderstanding terrorism" (p. 15), and "prefer appearing 'tough on terrorism' to effectively combatting it at home" (p. 123). Sageman argues that media reporting is "significantly flawed" and "hysterical" (p. 20), and suggests that, "the media and politicians seldom pass up any opportunity to embellish and sensationalise news events" (p. 170). The combination of these two factors is "a great inflation of the terrorist threat in the United States, resulting in popular hysteria" (p. 21).

The focus on the threat to the 'West' is understandable in some ways - it is the threat to one's own state that the media and politicians are concerned with and attempt to mitigate. But, whilst Sageman is clear from the outset that he will focus on this threat, expanding this element of the research to include threats to other, non-Western, countries would be beneficial as a comparative study and to further highlight that victims of terrorism are more likely to reside in 'non-Western' than 'Western' countries, another common misunderstanding about terrorism. A drawback of this decision is that attacks committed in 'non-Western' countries, but directed against 'Westerners' are omitted, including attacks like the 2002 Bali nightclub bombing that killed many locals, but also more than one hundred 'Westerners'.

The third and fourth chapters focus on the thorny topic of radicalization. Sageman refers to the 'arrival' of the term among terrorism scholars, but argues - as he has elsewhere (Sageman, 2014) "our understanding of this process remains stagnant" (p. 90). Sageman suggests that radicalization actually takes two forms: the first involves the "acquisition of extreme ideas, or cognitive radicalization"; the second refers to the "turn to violence or behavioral radicalization", based on these ideas (p. 90). Notably, he suggests that McCauley and Moskalenko's approach cannot necessarily explain the latter of these two approaches (p. 112). Central to Sageman's thesis is identity: “in the turn to political violence, identity trumps both ideology and self-interest" (p. 174), and traces this process starting with the development of a politicised social identity, the solidification of a community centred on this identity and the emergence of leaders, or "prototypes" (p. 125), establishing norms of 
behavior. It is then state mistreatment of the group or its community, or declining confidence in non-violent methods that escalate the conflict to violence (p. 130).

As in Leaderless Jihad (2008), Sageman highlights the centrality of the group, and group dynamics, to his understanding of the development of terrorist plots. As others have, the author concludes with advice on a measured response to terrorism. Sageman suggests it is crucial to undermine group coherence (p. 166), to separate violent and non-violent actors (p. $167)$ and behave responsibly, avoiding extra-legal or emergency measures where possible (p. 173). This shrewd advice may lack the political showmanship of more draconian measures, but Sageman's excellent and challenging critique of the established knowledge of terrorism may help to demonstrate that less is more.

\section{Conclusion}

These fours texts, although varied in form and focus, taken together further emphasize the importance of understanding identity, and the lessons that can be learned from engaging with historical examples of terrorist activity. In terms of identity, for Sageman the key level of focus is the group, and the ways in which group norms and behaviors contribute to a common process of escalating political action. McCauley and Moskalenko also highlight the centrality of group dynamics, but consider individual and societal factors equally important to radicalization. Aggarwal's account of the Taliban develops the group theme further by revealing the group identities that the Taliban are trying to cultivate in their messaging. Finally, Brenner's work cautions against falling into the trap of creating binary civilizational divides, and of treating Al Qaeda or its predecessors as representative of the out-group. These insights demonstrate the valuable contributions that psychology can provide in answering some of the most important questions related to terrorism and political violence in its many forms.

In terms of drawing from history, Brenner's work highlights that the threat posed by $\mathrm{Al}$ Qaeda and IS has a variety of historical parallels and, like Sageman, suggests a restrained, judicial response is the best course of action. Aggarwal and Sageman focus on more recent historical developments to draw out patterns in the development of terrorist actors and activity, and McCauley and Moskalenko take their readers to $19^{\text {th }}$ century Russia to highlight how our understanding of why people kill can be informed by engaging with the past. 
Terrorism research often focuses narrowly on the latest developments and too often ignores the lessons of history. These studies indicate that to do so weakens our understanding of a variety of important phenomena.

Each of these texts contributes expertise of a slightly different facet of our understanding of political violence, but all four make important contributions to a variety of key debates in shaping our understanding of, and response to, terrorism. Furthermore, the variety of methodological approaches adopted highlights the importance of interdisciplinary endeavours in studying violent political action.

Nick Brooke, Centre for the Study of Terrorism and Political Violence, School of International Relations University of St Andrews, nstb@st-andrews.ac.uk 


\section{References}

Aggarwal, N. K. (2016). The Taliban's Virtual Emirate: The Culture and Psychology of an Online Militant Community. New York: Columbia University Press.

Anderson, B. (1991). Imagined Communities: Reflections on the Origin and Spread of Nationalism [2 ${ }^{\text {nd }}$ Edition]. London: Verso.

Brenner, W. J. (2016). Confounding Powers: Anarchy and International Society from the Assassins to Al Qaeda. Cambridge: Cambridge University Press.

Hegghammer, T. (2017) Jihadi Culture: The Art and Social Practices of Militant Islamists. Cambridge: Cambridge University Press.

Huntington, S. P. (1993) The Clash of Civilizations? Foreign Affairs, Summer 1993.

McCauley, C and Moskalenko, S. (2017). Friction: How Conflict Radicalises Them and Us [Revised and Expanded Edition]. Oxford: Oxford University Press.

Sageman, M. (2014). The Stagnation in Terrorism Research. Terrorism and Political Violence, 26(4), 565-580.

Sageman, M. (2017). Misunderstanding Terrorism. Philadelphia, PA: University of Pennsylvania Press. 